\title{
Desempenho educacional: foi tudo determinado 100 anos atrás?†
}

\author{
Irineu de Carvalho Filho* \\ Renato Perim Colistete**
}

\begin{abstract}
RESUMO - Este artigo tem como tema a persistência institucional no desenvolvimento econômico de longo prazo. Nós investigamos o desempenho histórico da educação em uma das sociedades de maior crescimento e maior nível de desigualdade no século XX - o estado de São Paulo. Apoiados em evidências detalhadas sobre a propriedade da terra e educação, nós avaliamos o papel de fatores como concentração da terra, imigração e o tipo de atividade econômica na determinação da oferta e demanda de educação no início do século XX, bem como o grau em que tais fatores podem contribuir para explicar o desempenho educacional e os níveis de renda per capita nos dias de hoje. Nós chegamos a dois resultados centrais: um efeito positivo e duradouro da presença de imigrantes, bem como um impacto negativo da concentração da terra sobre a oferta de educação. Trabalhadores agrícolas imigrantes estabeleceram escolas comunitárias, pressionaram por financiamento público para essas escolas ou, ainda, reivindicaram a abertura de escolas públicas. Os efeitos do aumento inicial da instrução pública elementar podem ser detectados mais de 100 anos depois na forma de melhor desempenho no ensino secundário e maiores níveis de renda per capita nos municípios de São Paulo. Esses resultados sugerem um mecanismo adicional que gerou maior desigualdade entre regiões: aquelas regiões que receberam imigrantes oriundos de países em que a educação pública já havia se estabelecido beneficiaram-se da adoção da ideia revolucionária da educação pública.
\end{abstract}

Palavras-chave: Educação pública. São Paulo. História econômica. Desenvolvimento econômico. Café. Imigração. Desigualdade.

\section{INTRODUÇÃO}

A observação de que o desenvolvimento econômico é o resultado da interação de processos persistentes e cumulativos de longo prazo, atraiu a atenção dos estudiosos das diferenças de desempenho econômico entre países para o campo da história econômica. Do ponto de vista brasileiro, talvez a questão mais importante e difícil a respeito do desempenho econômico de longo prazo é explicar porque o Brasil e o resto da América Latina não se desenvolveram da mesma maneira que as ex-colônias britânicas da América do Norte ao longo do século XIX. Essa questão motivou Stanley Engerman e Kenneth Sokoloff a investigar as diferenças entre as instituições como prováveis causas fundamentais para o desempenho econômico diferenciado

\footnotetext{
† Este texto não representa a visão do Fundo Monetário Internacional, mas sim a visão do autor que não representa a visão do FMI ou política do FMI.

*Doutor em Economia pelo Instituto de Tecnologia de Massachusetts. É Economista no Departamento de Pesquisa do Fundo Monetário Internacional. Endereço eletrônico: idecarvalhofilho@imf.org.

${ }^{* *}$ Doutor em História Econômica pela Universidade de Oxford. É professor de História Econômica no Departamento de Economia da Universidade de São Paulo. Endereço eletrônico: rcolistete@usp.br.
} 
da América Latina e dos Estados Unidos da América, em uma série notável de artigos a partir do final da década de $1990 .{ }^{1}$

Em nosso artigo intitulado "Education Performance: Was It All Determined 100 Years Ago? Evidence From São Paulo, Brazil', ${ }^{2}$ nós utilizamos uma abordagem histórica e econométrica para investigar se as diferenças atuais no desempenho educacional e no nível de renda per capita dos municípios do estado de São Paulo são relacionadas a fatores de longo prazo como a concentração fundiária, a presença de imigrantes e o tipo de atividade econômica no início do século XX.

Nas seções seguintes nós apresentamos as motivações de nossa pesquisa, os dados utilizados e as principais conclusões a que chegamos. Os resultados mostram que não só a concentração da propriedade da terra, mas mecanismos ainda pouco explorados pela literatura, associados à presença de imigrantes nas sociedades do Novo Mundo, podem ter sido decisivos para explicar o desempenho educacional e econômico no longo prazo.

\section{A EXPANSÃo EDUCACIONAL EM SÃO PAULO}

O nosso ponto de partida situou-se no começo do século XX, um período de rápido crescimento e grandes transformações na economia e sociedade brasileira. A partir da década de 1850, o estado de São Paulo tornou-se um dos principais centros da produção agrícola de exportação (principalmente café) baseada no trabalho escravo. A elite escravocrata paulista do século XIX demonstrou pouco interesse em garantir educação pública primária para as massas, ao mesmo tempo em que a Província de São Paulo não dispunha de recursos fiscais para estender a educação primária para a maioria da população. Como resultado, apesar do boom exportador já ter então iniciado uma expressiva acumulação de capital nas zonas produtoras de café, São Paulo possuía apenas 14 crianças matriculadas em escolas primárias para cada 1.000 habitantes livres em 1872, proporção exatamente igual à média nacional e inferior à de várias outras províncias como Sergipe (29), Rio Grande do Sul (23), Santa Catarina (21), Espírito Santo (21), Amazonas (21), Maranhão (16) e Alagoas (15). ${ }^{3}$ Sabemos, entretanto, que tal situação não perdurou. O impressionante aumento das exportações do café enriqueceu São Paulo e o governo provincial passou a subsidiar massivamente a imigração europeia diante da desagregação da instituição escravista nas fazendas, com um enorme efeito na entrada de imigrantes eu1 ENGERMAN, S. L.; KENNETH L. S. Factor Endowments, Inequality, and Paths of Development among New World Economies: A View from Economic Historians of the United States. ENGERMAN, S. L.; MARISCAL, E. V.; SOKOLOFF, K. L. The Evolution of Schooling in the Americas, 1800-1925.

2 Disponível em: <http://mpra.ub.uni-muenchen.de/24494/>.

3 BRASIL, Instituto Brasileiro de Geografia e Estatística. Anuário Estatístico do Brasil, 1939/1940. Rio de Janeiro: IBGE, 1939/40. 
ropeus. Com a abolição da escravidão e a proclamação da República, um novo pacto federativo foi desenhado, dando um renovado impulso às receitas fiscais de estados que, como São Paulo, possuíam um setor exportador dinâmico, já que seus governos ganharam pleno controle sobre os recursos dos impostos sobre exportação. ${ }^{4}$

Nas décadas seguintes, São Paulo passou a assumir gradualmente um papel de liderança na oferta de educação elementar. Em 1907, as matrículas nas escolas primárias de São Paulo - 34 alunos por 1.000 habitantes - já eram maiores do que a média nacional. Trinta anos mais tarde, as matrículas em escolas primárias no estado chegaram a 101 crianças por 1.000 habitantes, um índice inferior apenas aos de Santa Catarina (128) e da Capital Federal (123). ${ }^{5}$

Tentar entender esse salto dado por São Paulo na oferta de educação pública elementar em um relativamente curto espaço de tempo foi uma das principais motivações para a realização da nossa pesquisa. Além disso, constatamos que havia diferenças substanciais entre os municípios de São Paulo no comprometimento das suas receitas fiscais com gastos em educação primária. Como explicar tais diferenças?

Primeiramente, nós investigamos os determinantes do desenvolvimento das escolas públicas primárias locais no começo do século XX. Partimos da premissa, baseada nas experiências históricas dos países desenvolvidos, de que a provisão de educação pública foi em geral um fenômeno associado à democratização da sociedade. ${ }^{6}$ Portanto, onde o poder econômico e político era mais concentrado, a expectativa era a de que a introdução da educação pública para as massas fosse retardatária ou incompleta. Para capturar esse efeito, nós estimamos medidas de concentração da posse da terra e de extensão do sufrágio. ${ }^{7}$

Consideramos também que a presença de imigrantes estrangeiros, em sua esmagadora maioria colonos em fazendas de café, tenderia a exercer efeitos incertos sobre a provisão da educação pública no começo do século XX. Por um lado, visto que estrangeiros tinham menos acesso ao voto que nacionais, o poder local tenderia a ser mais oligárquico nos municípios onde a presença de imigrantes estrangeiros fosse significativa. Por outro lado, muitos dos colonos estrangeiros eram originários de países onde a escola pública era uma instituição mais arraigada que no Brasil do começo do século XX. As taxas de matrícula de crianças de 5 a 14 anos ultra-

4 LOVE, J. São Paulo na Federação Brasileira, 1889-1937. São Paulo: Paz e Terra, 1982, cap. 8.

5 BRASIL, Anuário Estatístico do Brasil, 1939/1940, p. 1.398.

6 LINDERT, P. Growing Public: Social Spending and Economic Growth Since the Eighteenth Century. Cambridge: Cambridge University Press, 2004.

7 Para os dados de produção, emprego agrícola e posse de terra, São Paulo, Secretaria dos Negocios da Agricultura, Commercio e Obras Publicas, Estatística Agrícola e Zootécnica do Estado de São Paulo, 1904-1905 (São Paulo, 1904-5). Para os dados eleitorais: São Paulo, Repartição de Estatística e do Archivo de São Paulo, Annuario Estatístico do Estado de São Paulo, 1904 (São Paulo: Typographia do "Diário Official”, 1907). 
passavam 35 por cento na Itália em 1890, enquanto no Brasil atingiam 10 por cento em $1900{ }^{8}$ Para capturar o efeito da presença de imigrantes, nós usamos a participação dos estrangeiros na força de trabalho e na posse de terra em cada município.

Outro aspecto importante seria o tipo de atividade econômica predominante nos municípios, que segundo alguns autores conspiraria contra o desenvolvimento da educação pública e outras instituições democráticas em São Paulo. A cultura do café praticada em São Paulo era baseada na grande propriedade e, até o fim do século XIX, no trabalho compulsório dos escravos. Se a grande propriedade cafeeira teve consequências para o desenvolvimento da educação pública, esperar-se-ia que esta fosse retardada nos municípios onde o café era predominante.

O nosso passo seguinte foi examinar a existência de uma conexão entre o passado e o desempenho recente, isto é: os municípios que assumiram a dianteira na oferta de educação primária no início do século XX ainda se beneficiam dessa vantagem inicial?

\section{EXPLICANDO O DESEMPENHO EDUCACIONAL}

Nossos resultados podem ser ilustrados em um gráfico, que relaciona as notas do Exame Nacional de Ensino Médio (ENEM) dos municípios de São Paulo em 2007 e os gastos municipais per capita em educação em 1904-7.

GRÁFICO 1 - NOTA MÉDIA PADRONIZADA NO ENEM DE 2007 E GASTOS COM EDUCAÇÃO PÚBLICA NA DÉCADA DE 1900 POR MUNICÍPIOS EM SÃO PAULO

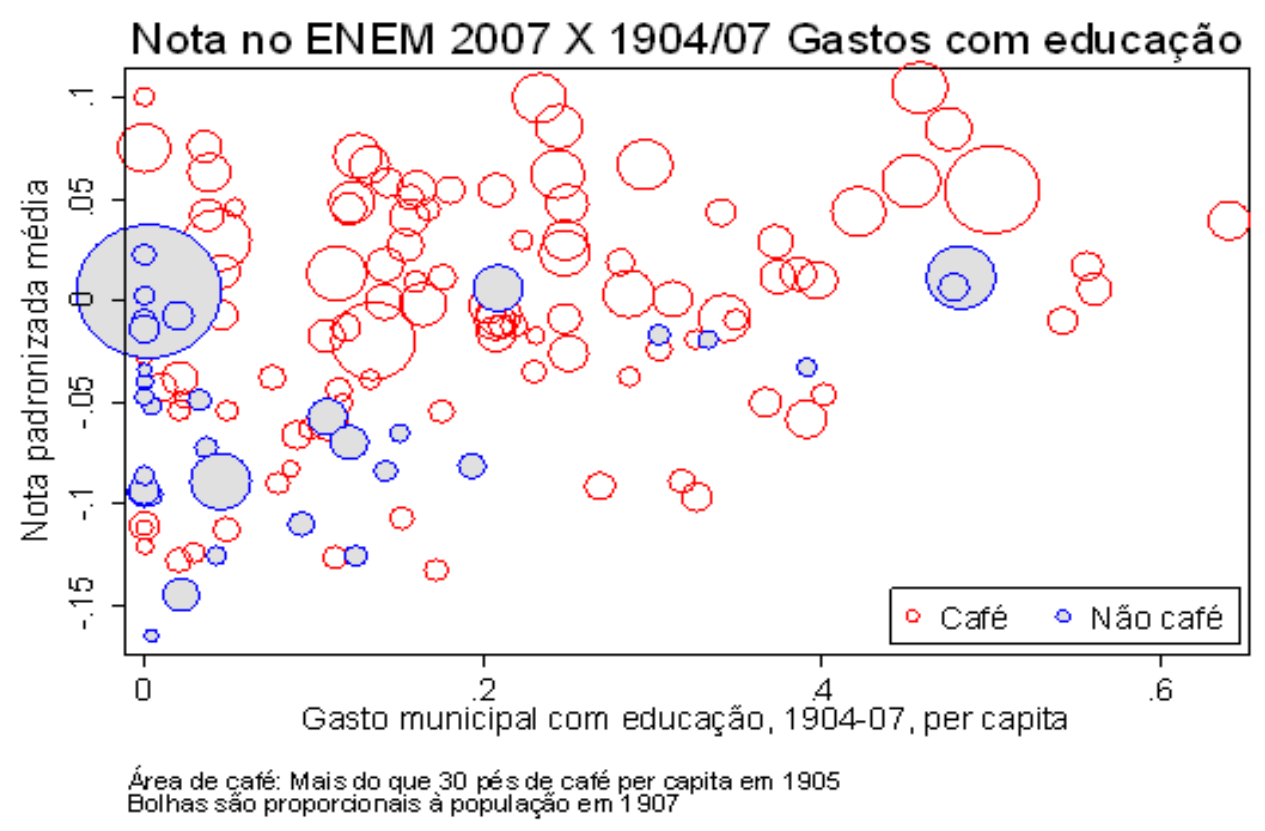

Este gráfico resume várias informações importantes. Primeiro, é possível ver que a receita do imposto do café parece estar associada a um nível mais elevado de despesa per capita

8 Lindert, Growing Public, p. 91-93.

106 
do governo municipal em educação no começo do século XX, uma vez que os municípios que não eram especializados em café (isto é, aqueles com menos de 30 pés de café por habitante) concentram-se perto do nível de gasto zero. Segundo, existe uma clara relação positiva entre os gastos públicos em educação do governo local cem anos atrás e o desempenho no ENEM hoje em dia. Terceiro, essa relação entre desempenho passado e recente é válida tanto para municípios especializados em café ou não, mas dentre os municípios com gastos em educação pública maiores do que a média do estado, a quase totalidade era especializada em café cem anos atrás. Quarto, a decisão por financiamento local das escolas públicas não foi trivial, como podemos ver pela presença de muitos municípios com gasto zero. ${ }^{9}$ Finalmente, parece haver uma associação positiva entre a população (uma proxy de urbanização) dos municípios em 1907 e o desempenho acadêmico hoje em dia, mesmo depois de controlar pelos gastos municipais em educação cem anos atrás.

Os nossos testes empíricos revelaram duas causas centrais que contribuem para explicar os resultados acima. Primeiro, a concentração da propriedade da terra: quanto maior a concentração da terra, menor tendia a ser a oferta de educação pública primária nos municípios de São Paulo no início do século. Esse resultado converge com as pesquisas de Engerman e Sokoloff sobre o papel da desigualdade da propriedade da terra como um fator determinante de instituições excludentes, com consequências sobre o crescimento de longo prazo.

Segundo, e talvez mais surpreendente, nossos testes indicaram que a presença de trabalhadores rurais originários de países onde a educação pública era mais arraigada é associada com um aumento na oferta de educação pública no estado de São Paulo no começo do século XX. Nossa explicação para esse resultado é que a chegada de milhares de imigrantes transformou o estado de São Paulo em várias dimensões. Os imigrantes vinham de países e regiões com diferentes tradições cívicas e políticas, frequentemente com níveis educacionais mais elevados e com diferentes expectativas sobre a qualidade dos serviços públicos. Como notou Vincenzo Grossi, diplomata italiano em São Paulo na época:

"Em geral, os colonos comem bem, trabalham menos e estão talvez em melhor situação do que na Itália (...) Mas você se esqueceu de um fator importante, o aspecto ético-social: o homem precisa mais do que pão apenas!. De fato, do ponto de vista da moral, instrução e educação, a vida dos pobres colonos nas plantações, particularmente aquelas longe dos centros habitados, deixa muito a desejar e apresenta muitos pontos de analogia com a vida dos homens primitivos, pré-históricos ou contemporâneos." ${ }^{10}$

9 A bolha grande à esquerda do gráfico 1 se refere à Capital (São Paulo), que recebia fundos do governo estadual.

10 GROSSI, V. Storia Della Colonizzazione Europea al Brasile e Della Emigrazione Italiana Nello Stato

di S. Paulo. Roma: Oficina Poligrafica Romana, 1905. 
Do descompasso entre as expectativas dos imigrantes e a realidade nas fazendas, há evidências de que os imigrantes mobilizaram-se para pressionar por escolas públicas ou organizar suas próprias escolas comunitárias desde o final do século XIX. No bairro dos Pires, na cidade de Limeira, ex-colonos alemães da Fazenda Ibicaba e outras fazendas organizaram-se, compraram um terreno e abriram uma escola em 1874. Em Indaiatuba, imigrantes italianos e suíços reuniram-se para instalar uma escola primária. Nessa cidade, uma colônia de imigrantes suíços, a Colônia Helvetia, organizou uma escola rural em 1893. Mais tarde, a Câmara Municipal consistentemente votou para melhorar os salários dos professores e garantir subsídio público às escolas rurais comunitárias (como aquela da Colônia Helvetia), apesar da pequena disponibilidade de recursos. Em 1906, Indaiatuba gastou 17,3\% de seu orçamento com educação, enquanto sua vizinha Itu, com uma população bem maior, gastou somente $2,3 \%$ das receitas municipais. Quando uma pesquisa levada a campo pela Câmara Municipal de Indaiatuba concluiu que muitas crianças pobres não iam à escola porque suas famílias não tinham sequer recursos para vestí-las adequadamente, a Câmara aprovou uma lei instituindo um fundo de assistência escolar distribuindo dinheiro para as famílias pobres mandarem suas crianças para a escola (note a similaridade com programas de transferências condicionais modernos, como o Bolsa Escola/Bolsa Família). O fundo foi fixado em 1,5\% do orçamento municipal, complementado por doações da população da cidade (ALVES, 2007, p. 73-134; GRININGER, 1991, cap. 6). ${ }^{11}$

Ou seja, onde não havia escolas públicas estabelecidas, os imigrantes organizaram suas próprias escolas comunitárias, pressionaram por financiamento público para essas escolas ou, ainda, reivindicaram a abertura de escolas públicas. Um século mais tarde e várias décadas depois do café ter perdido sua importância relativa para a economia do estado, os municípios que foram líderes no financiamento da instrução pública pelo governo local ainda estão em vantagem em termos de desempenho escolar no ensino secundário assim como em renda per capita no estado de São Paulo.

Esses resultados têm implicações amplas, pois sugerem uma interpretação alternativa para os processos que diferenciaram as Novas Europas (EUA, Canadá, Austrália e Nova Zelândia) do resto das ex-colônias: a imigração em massa de europeus durante o século XIX pode ter trazido as instituições educacionais para o Novo Mundo. Essa interpretação ajudanos a entender também o declínio relativo (e às vezes, absoluto) de áreas como o Caribe e o 11 Sobre Limeira, ver Maria Cristina S. Bezerra, Imigração, Educação e Religião: um Estudo Histórico-Sociológico do Bairro dos Pires de Limeira, uma Comunidade Rural de Maioria Teuto-Brasileira (Dissertação de Mestrado, Universidade Estadual de Campinas, 2001). Para Indaiatuba, Silvane R. L. Alves, A Instrução Pública em Indaiatuba: 1854-1930. Contribuição para a História da Educação Brasileira (Dissertação de Mestrado, Universidade Estadual de Campinas, 2007) e Valdemar Grininger, Imigração Suíça em São Paulo: A História da Colônia Helvetia (Dissertação de Mestrado, Universidade Estadual de Campinas, 1991).

108 
Nordeste brasileiro. Como essas regiões sofreram durante o século XIX com o declínio do preço do açúcar, a perda direta das receitas de exportação pode ter sido amplificada pela perda dos benefícios potenciais da entrada de imigrantes e suas instituições educacionais, já que tais regiões não foram capazes de atrair um fluxo significativo de trabalhadores da Europa durante a era da imigração em massa.

\section{REFERÊNCIAS}

ALVES, Silvane R. L. A Instrução Pública em Indaiatuba: 1854-1930. Contribuição para a História da Educação Brasileira. Dissertação (Mestrado) - Universidade Estadual de Campinas, 2007.

BEZERRA, Maria Cristina S. Imigração, Educação e Religião: um Estudo Histórico-Sociológico do Bairro dos Pires de Limeira, uma Comunidade Rural de Maioria TeutoBrasileira. Tese (Mestrado) - Universidade Estadual de Campinas, 2001.

BRASIL, Instituto Brasileiro de Geografia e Estatística. Anuário Estatístico do Brasil, 1939/1940. Rio de Janeiro: IBGE, 1939/40.

ENGERMAN, S. L.; KENNETH L. S. Factor Endowments, Inequality, and Paths of Development among New World Economies: A View from Economic Historians of the United States. In: HABER, S. (Ed.). How Latin America Fell Behind: Essays on the Economic Histories of Brazil and Mexico, 1800-1914. Stanford: Stanford University Press, 1997.

ENGERMAN, S. L.; MARISCAL, E. V.; SOKOLOFF, K. L. The Evolution of Schooling in the Americas, 1800-1925. In: ELTIS, D.; LEWIS, F. D.; SOKOLOFF, K. L. (Eds.). Human Capital and Institutions. A Long-Run View. Cambridge: Cambridge University Press, 2009.

GRININGER, V. Imigração Suiça em São Paulo: A História da Colônia Helvetia. Tese (Mestrado) - Universidade Estadual de Campinas, 1991.

GROSSI, V. Storia della Colonizzazione Europea al Brasile e della Emigrazione Italiana nello Stato di S. Paulo. Roma: Oficina Poligrafica Romana, 1905.

LINDERT, P. H. Growing Public: Social Spending and Economic Growth Since the Eighteenth Century. Cambridge: Cambridge University Press, 2004.

LOVE, J. L. São Paulo na Federação Brasileira, 1889-1937. São Paulo: Paz e Terra, 1982.

SÃO PAULO, Repartição de Estatística e do Archivo de São Paulo. Annuario Estatistico do Estado de São Paulo, 1904. São Paulo: Typographia do Diário Official, 1907.

SÃO PAULO, Secretaria dos Negocios da Agricultura, Commercio e Obras Públicas. Estatística Agrícola e Zootécnica do Estado de São Paulo, 1904-1905. São Paulo, 1904-5. 
